\title{
STAFF DEVELOPMENT AS A CONDITION FOR COMPUTER INTEGRATION
}

\author{
Ingeborg Janssen Reinen and Tjeerd Plomp \\ Faculty of Educational Science and Technology, University of Twente, The Netherlands
}

Introduction

Staff development is a basic and necessary component of the continuing education of teachers, administrators and other staff as they extend their professional or technical knowledge (Orlich, 1989). Codianni and Wilbur (1983) compared the findings of seventeen major studies on effective schools and found systematic staff development as being one of six important aspects of effective schools. Besides regular updating of knowledge in one's subject, professional development and assistance are important for both the dissemination and implementation of educational innovations (Fullan \& Stiegelbauer, 1991). Teachers need to learn new roles in order to work effectively with new programs and technologies (van den Akker, 1988). It is therefore no surprise that staff development and training is one of the factors that determine the success of implementing an innovation in the educational practice (Fullan \& Stiegelbauer, 1991). There are no reasons to expect that this should not also hold for the use of computers in education. The crucial role of staff development in the introduction of computers in the school is also emphasized by Moskowitz and Birman (1985), Walker (1986), Brody (1987) and the US Congress (1988).

Since the introduction of the computer in education, many authors claim that the beneficial aspects of computer use in education are related to the integration of computers in the existing subjects (e.g. Collis, 1988, Hunter, 1984). However, the findings of the first stage of the International Association for the Evaluation of Educational Achievement (IEA)-international research project 'Computers in Education' (Comped) revealed that the use of computers in existing subjects as an aid in teaching and learning is limited. In most countries participating in this study, the introduction of the computer in schools is predominantly occurring through the introduction of a new subject like computer education or informatics, while the use of computers in existing subjects is still an activity of a rather small group of teachers. The group of intensive computer using teachers will at the best not exceed 15\% (Pelgrum, in preparation).

One may argue that computer use in existing subjects is not fully integrated because this form of using computers is the most complex part of the innovation: this type of computer use requires (unlike the introduction of a new and additional subject like 
computer education) a change in the role of the teachers, as well as adaptations of the existing curricula (Walker, 1986). As Tobin (1988, p. 223) states, '... adequate hardware, high-quality courseware and administrative support are important, but the teachers' attitude and consequent behavior will determine the impact of the microcomputer in the classroom'. This leads to the conclusion that the limited use of computers in the different subjects may only be partly explained by the limited availability of hardware and educational software in a particular grade or subject, but that other factors also contribute to the low use of computers in existing subjects. Earlier research shows that staff development is such a factor and Comped data also demonstrate that this factor is important to consider.

First of all, Pelgrum and Schipper (1992), using Comped data, developed a measure for computer integration in the class. The number of subject matter topics for which a teacher indicates computer use serves as a measure for the integration of computers in that subject area. In order to compensate for the fact that for different subjects matter domains (mathematics, science and mother tongue) the total number of topics for which computers are being used varies between teachers, the maximum possible scores for each subject were rescaled to a 10-point scale. Pelgrum and Schipper found that the integration measure is related to certain elements teachers know or can do (like evaluating usefulness of software and adapt instructional software). This result indicates that integration of computers in the lesson is partly determined by the knowledge and skills of teachers.

The Comped data show further that the lack of knowledge of teachers and insufficient training opportunities are considered to be two major problems in the use of the computer in educational practice. Stasz and Shavelson (1985) already mentioned this problem '...the numbers of computers entering the schools are increasing at an overwhelming rate, far outstripping the schools' ability to prepare teachers to use the new technology'. However, teachers themselves consider their lack of knowledge and insufficient training opportunities less frequently a problem than principals and computer coordinators (Pelgrum \& Plomp, 1991).

A third indication of the relevance of staff development can be derived from a LISREL analysis on the Comped data by Tuijnman and ten Brummelhuis (in preparation). They fitted a LISREL model for six countries, consisting of three dependent variables, namely computer use, teacher competence and readiness, and monitoring and problem coping strategy. One of the independent variables in the models was related to internal staff development. Tuijnman and ten Brummelhuis found that in several countries staff development is related to computer use, teacher competence and strategies to monitor computer use and to the ability to cope with problems.

The results of the Comped study may shed some light on the actual practice of staff development in the schools and its relation with computer use (or non-use) of existing subject teachers. In this paper we will describe the status of knowledge and skills (of teachers in existing subjects) in educational computer use, their involvement in teacher training, and we will relate these to the actual use of computers in the classroom.

Another aspect of staff development is the communication and interaction among teachers, about which some results will be presented as well. Although staff development can be studied on school and on school-transcending level (for example support to teacher training, the role of the principal in the innovation), this paper will be restricted to the teacher level. 
In the next section, the general research interest as indicated above will be operationalized into several research questions and the relevant variables will be explained as well as the data sources. In the following section results are presented, while in a concluding section the implications of the reported findings will be discussed.

\section{Data Source and Research Questions}

First of all, a definition of staff development is necessary as different terms like professional development, in-service training, professional growth, staff development and in-service education are being used in the literature, with the term chosen more a matter of author preference than of any significant difference in meaning (Orlich, 1989). Following Orlich (1989, p. 5-6) "Staff development subsumes in-service education and also addresses the larger issue of developing organizational problem-solving capacities and leadership skills" regarding the use of computers in the educational practice. "The totality of building human and institutional resources in the organization becomes the goal of staff development." This means that staff development also includes, besides in-service training, classroom-based support, assessment (reflection on the part of the teacher as well as reflection on the validity of the training activities) and dissemination (teachers teaching teachers and team teaching) (Zappone, 1991). For this reason, in the results section a paragraph dealing with communication and interaction aspects is included.

Following Orlich (1989), in-service education can be operationalized further as: "programs or activities that are based on identified needs; that are collaboratively planned and designed for a specific group of individuals; that have a very specific set of learning objectives and activities; and that are designed to extend, add, or improve immediate joboriented skills, competencies, or knowledge" leading to changes in teachers' thinking and classroom behavior, "...with the employer paying the cost".

Within the perspective of the Comped study, it is not possible to distinguish between training received during in-service training or initial training. The analysis presented in this paper applies for both pre- and in-service training.

The data used in this paper were collected in 1989 in the 'Computers in Education' study. More details about this study are described in the paper by Pelgrum and Plomp also included in this issue. The present paper presents data across countries. The number of computer-using existing subject teachers included in the survey per country is too small to find variation; and as it is important in a first exploration to study variation in the phenomena dealt with, data from all countries are combined.

As the most beneficial aspects of computer use are expected to be found in existing subject matter areas, we will focus in this paper on teachers of the existing subjects (which are in the Comped study: mathematics, science and mother tongue), leaving out teachers of computer education. The teachers of existing subjects are considered as a whole because distinguishing the different subjects would leave us with too few cases in each subject matter domain. In addition, we will restrict ourselves to secondary education teachers.

The following research questions will be addressed:

1. What experience, knowledge and skills do teachers have concerning computers and their use in education, and how are these related to training?

2. Is there a relation between training received and actual practice of computer use in the existing subject lessons? 
3. Which teachers participated in training activities and what topics were covered in their training?

4. Is communication and interaction among teachers (being an aspect of staff development) an important indicator for computer integration?

As Becker (1992) states, it is important to study how exemplary teachers (that is, teachers who are reputedly expert computer-users in schools) came to use computers differently from other teachers; whether this be their personal background, their beliefs and philosophy of education or characteristics of their work environment. Differences found will help us to understand the barriers that exist for many teachers in using the computer.

For a definition of exemplary teachers (similar to Becker's definition but consisting of less variables), the measure for integration developed by Pelgrum and Schipper (1992) is used. They defined a 10-point scale based on the number of subject matter topics for which teachers of the existing subjects (mathematics, science, mother tongue) indicate computer use. For the purpose of this article, we define three categories of using teachers: low integrators (with score 1, 2 or 3 on the 10-point scale of number of topics in which computers are used), mean integrators (with score 4, 5, 6, or 7) and high integrators (with score 8,9 or 10). These three subgroups and the group of non-using existing subject teachers will be compared on a number of variables. The number of respondents in each group across countries is indicated in Table 1.

Table 1: Number of Respondents in Each Group of Integrators of Existing Subject Teachers

\begin{tabular}{lcccc}
\hline & \multicolumn{5}{c}{ number of cases } \\
Group of teachers & $\mathrm{n}$ & $\%$ & lower secondary schools & upper secondary schools \\
\hline non-users & 4664 & 81 & $\mathrm{n}$ & $\%$ \\
low integrators & 565 & 10 & 7002 & 84 \\
mean integrators & 352 & 6 & 601 & 7 \\
high integrators & 167 & 3 & 439 & 5 \\
\hline
\end{tabular}

To answer the research questions, variables like the knowledge and skills of teachers, whether training was received or not, the amount of training received, content of training, the number of years a teacher works with the computer, the actual use of the computer in the class, and issues related to communication and interaction will be included in the analysis.

We hypothesize the following:

a. The integration of computer use in existing subjects is correlated with the number of years the teacher works with computers. Rationale: as stated in the introduction, 
introducing computers in existing subjects is an complex innovation; Walker (1986, p. 33) mentions that

if even a small part of the visionary dreams of computer-based education is to be realized, major changes will be required in the day-to-day activity and interaction patterns in classrooms...Developing these new patterns will require collaborative effort on a large scale sustained over a decade or more.

b. High integrators know more than other subgroups of teachers, and the knowledge and skills base of teachers is (partly) determined by training. Rationale: as stated in the introduction, lack in teachers' knowledge and skills is seen as a problem and is expected to be one of the causes of the limited use of computers in existing subjects in 1989 , the year of data collection of Comped.

c. The content of training is related to the actual use of computers in the class. Rationale: assuming that knowledge and skills are related to training received (as stated above) and that limited knowledge and skills partly determine limited use of the computer in the class, it is expected that training is related to actual use as well.

d. Teachers who have had training in certain aspects of educational computer use are more likely to use the computer in their lessons than the group who did not receive any training in this area. Rationale: as use of the computer in the class is a complex change requiring a lot of pedagogical and organizational adaptations, having had training in these aspects is expected to have an influence.

e. Inter-relationships among teachers (in the form of communication and interaction) contributes to computer integration. Rationale: in innovation literature (e.g. Fullan \& Stiegelbauer, 1991), the interaction basis among teachers is mentioned as one of the important factors influencing the success of implementation.

\section{Results}

\section{Years of Instructional Use}

As described above, one may expect that the amount of computer experience of teachers influences the extent to which they use computers in their lessons. Table 2 shows the results of a breakdown of the number of years teachers use computers for instructional purposes in their subject matter by the amount of computer integration. Non-using teachers are not included as they do not use the computer for instructional purposes. Due to the fact that the distributions are rather skewed, a non-parametric test has been used to test the differences of means between the subgroups.

Using the Wilcoxon-Rank-Sum test, a significant difference is found between all combinations of two subgroups of using teachers in the number of years they work with the computer in their lessons (all with $\mathrm{p}<0,01$ ), except in upper secondary schools, between the group of mean and high integrators. The expectation that years of experience is an important factor in the process of integrating computers in existing subjects is indeed confirmed and it seems that, at least partly, the process of implementing this innovation is a matter of time. 
Table 2: Mean Number of Years Each Subgroup of Using Teachers Across Countries is Working with Computers for Instructional Purposes

\begin{tabular}{lcc}
\hline Group of using teachers & $\begin{array}{l}\text { mean number of years (s.e.) } \\
\text { lower secondary education }\end{array}$ & $\begin{array}{l}\text { mean number of years (s.e.) } \\
\text { upper secondary education }\end{array}$ \\
\hline low integrators & $2.77(0.09)$ & $3.60(0.12)$ \\
mean integrators & $3.19(0.10)$ & $3.96(0.13)$ \\
high integrators & $3.72(0.17)$ & $4.23(0.18)$ \\
\hline
\end{tabular}

Knowledge and Skills

Teachers who are willing to integrate computers in their subject matter area need knowledge about and skills in using computers. In order to find out what teachers themselves think they know about or can do with computers, so-called self-rating scales were included in the teacher questionnaire consisting of three scales with yes/no questions: - knowledge scale: nine questions about knowledge of hardware and software;

- $\quad$ programming scale: five questions about programming skills;

- capability scale: eight questions about the ability of using the computer as a tool for, for example, word processing and computer assisted instruction.

The validity of this scale seems to be fairly good, as explained by Pelgrum and Plomp (1991).

In general they concluded that teachers in elementary school score lower on these selfrating scales than teachers in lower and upper secondary schools. One may expect that the computer education teachers in lower and upper secondary schools would have higher scores than the using teachers in other subjects. Although this trend can be observed in general, in many educational systems the scores of the using teachers do not differ greatly from those of the computer education teachers. Using teachers in existing subjects know more than their non-using colleagues. This general result is also found (see Table 3 ) when considering the four distinct subgroups of using teachers (non-users, low integrators, mean integrators and high integrators) and looking at the mean number of all self-rating items each respondent filled in.

In lower secondary education all three subgroups of using teachers and the groups of non-using teachers differ significantly on the self-rating scales, indicating that the group of high integrators has most knowledge and skills. Within upper secondary education only users and non-users and the groups of low and high integrators differ significantly.

For each self-rating item, a test on differences of means for the subgroups of teachers is performed. 
Table 3: Mean Number of Knowledge and Skill Self-Rating Items for Each Subgroup of Teachers

\begin{tabular}{lcc}
\hline Group of teachers & mean number of items (s.e.) & $95 \%$ conf.interval \\
\hline lower secondary education & $7.69(0.10)$ & $7.50-7.88$ \\
non-users & $11.82(0.27)$ & $11.30-12.34$ \\
low integrators & $13.49(0.33)$ & $12.84-14.15$ \\
mean integrators & $15.45(0.43)$ & $14.61-16.29$ \\
high integrators & & \\
upper secondary education & & \\
non-users & $8.86(0.08)$ & $12.91-13.91$ \\
low integrators & $13.41(0.25)$ & $14.08-15.13$ \\
mean integrators & $14.61(0.27)$ & $14.57-15.85$ \\
high integrators & $15.21(0.33)$ & 9.03 \\
\hline
\end{tabular}

For lower secondary education each pair of subgroups of teachers differ significantly on two items, namely 'I am capable of adapting instructional software to my needs' and 'I am capable of writing courseware for my own lessons'. Furthermore, 20 items show a difference between the using and the non-using group. Of these 20 items, 15 are also significantly different for the low integrators in comparison with the high integrators. These items are included in Table 4.

For upper secondary education the following was found: only on one item ('I can write a program for storing data on a diskdrive') significantly differed for all four groups of existing subject teachers. Twenty-one items differ between the using and non-using teachers, of which eight also differ for low and high integrators. These items are included in Table 4 as well. This table shows that, particularly in lower secondary education, capability items as well as items referring to programming are important in distinguishing low and high integrators. Given these findings, one may conclude that knowledge and skills in general, and these types of knowledge and skills particularly, are important for teachers when integrating computers in their lessons. The next logical step is to look at how teachers received their knowledge and skills.

Knowledge and skills can be gained by teachers either through some kind of training or by means of self-study. The contribution of self-study activities to the knowledge and skill base of teachers can not be determined from the Comped stage 1 data, which is why we restrict ourselves to training. 
Table 4. Self-Rating Items Showing a Significant Difference Between Non-Using Teachers and Using Teachers as well as Between Low and High Integrators

\begin{tabular}{l}
\hline Self-rating items on subscales \\
Lower secondary education \\
I know. \\
the trend in hardware development in the last 20 years \\
what 'file extensions' are \\
what a loop means in programming \\
what a 'bit' is defined as \\
the difference between RAM and ROM \\
Ican write a program for... \\
adding up numbers \\
using arrays \\
storing data on a diskdrive \\
sorting data into a certain sequence \\
printing the complete ASCII character set \\
Iam capable of... \\
exchanging data between different types of computers \\
copying files from one disk to another \\
loading a data set from a disk drive \\
creating a database file \\
evaluating the usefulness of software for my lessons \\
adapting instructional software to my needs* \\
writing courseware for my own lessons*
\end{tabular}

Self-ratıng 1tems on subscales
Upper secondary education
I know...
what 'file extensions' are
what a 'relational database' is like
what a 'bit' is defined as
I can write a program for ...
adding up numbers
using arrays
storing data on a diskdrive*
sortıng data into a certain sequence
I am capable of ....
exchanging data between different types of computers
adapting instructional software to my needs

* These items show a significant difference for all pars of subgroups of teachers 
The overall correlation between participation in training (yes/no) and the knowledge/skill base of teachers is 0.60 (lower secondary education), and 0.57 (upper secondary education), indicating that there is an association between training and knowledge base. This correlation is significant for all subgroups of teachers in both populations. This means that it is likely that teachers do receive part of their knowledge and skills via training (and probably also partly via self-study activities). In the context of implementing computers in education, this means that the training component in the innovation process is relevant and contributes to the integration of computers in existing subject matter areas. Given this finding, it is interesting to have a closer look at the training component.

Training

Teachers in the Comped project were asked which computer-related topics were covered during their initial or in-service teacher training. The questionnaire listed topics within five main categories: Computers and society (4 topics), Applications (14), Problem analysis and programming (5), Principles of hard- and software structure (3), and pedagogical/instructional aspects (5). Pelgrum and Plomp (1991) mention that computer education teachers learned more topics during their training than teachers of existing subjects, and that computer-using teachers of existing subjects learned more during training than their non-using colleagues. There is hardly any difference between lower and upper secondary schools in the content of topics in teacher training.

When combining the factor of whether training was received or not (regardless the number of topics which was covered in the training) with the four subgroups of existing subject teachers (non-users, low integrators, mean integrators and high integrators), it is (not surprisingly) found that (in lower secondary education) $88 \%$ of the users and $68 \%$ of the non-users have had some form of training; this difference is significant $(\mathrm{p}<0.01)$. For upper secondary schools these percentages are about $85 \%$ for the users and $63 \%$ of the non-users; again this difference is significant. No significant difference was found for either population between the three distinct user subgroups. This finding means that having had some training is no indication for the degree of integration of the computer in the existing subject matter area; it does only distinguish the group of users from non-users. A closer look at the number of topics covered during training and what topics are included in training may give more information.

A breakdown of the number of topics covered in teacher training by the amount of computer integration leads to the results represented in Table 5. The subgroups of existing subject teachers differ significantly on the number of topics covered in their training, except in lower secondary education between low and mean integrators and in upper secondary education between mean and high integrators. This means that, where having had training in general does not distinguish the using subgroups, the amount of training (in terms of number of topics) to some extent does because in both populations at least low and high integrators differ significantly on the amount of training received. This finding means that when introducing computers in education, it is not enough to give all teachers a course on how to use computers, dealing with only a few topics. The number of topics covered in teacher training also influences the amount of computer integration. training?

The question that arises now is: What the important topics to be covered in teacher 
Table 5: Mean Number of Topics Covered in (Pre- or Inservice) Trainıng Distınguished for the Four Subgroups of Teachers

Group of teachers mean number of topics (s.e.)

$95 \%$ con. interval for mean

\begin{tabular}{lrr}
\hline $\begin{array}{l}\text { lower secondary education } \\
\text { non-users }\end{array}$ & $5.22(0.10)$ & $5.04-5.41$ \\
low integrators & $8.15(032)$ & $7.52-8.78$ \\
mean integrators & $9.24(0.40)$ & $8.45-10.03$ \\
high integrators & $12.04(0.62)$ & $10.82-13.27$ \\
upper secondary education & & \\
non-users & $529(0.08)$ & \\
low integrators & $807(0.31)$ & $5.14-545$ \\
mean integrators & $999(0.38)$ & $7.46-868$ \\
high integrators & $10.39(0.45)$ & $9.25-10.73$ \\
\hline
\end{tabular}

As illustrated by a quote from Stasz and Shavelson (1985), this question was already asked quite some years ago: 'there is a lack of knowledge and agreement on the topics for and organization of staff development programs'.

However, it seems relevant to look at the content of tranning only if the training activities are indeed related to the actual use of the computer in the class. Although a relation is found between the number of topics taught in teacher traning and the amount of computer integration, a more detailed look is possible on the type of topics taught in the actual class practice.

Relation Training and Actual Use of Computers in the Classroom

In many schools, some computer-related topics are (also) taught outside formal computer education classes. Teachers of existing subjects were asked to indicate which computer related topics were taught in their subject matter class. The list of topics used for this question was a subset of the list of topics which could be part of teacher training and consisted of the first four categories: computers and society, applications, problem analysis and programming and principles of hard- and software structure.

The correlation between the number of topics covered in training and the number of computer topics taught in the class is for lower and upper respectively 0.39 and 0.35 for all existing subject teachers. For each subject separately, the correlation is respectively 0.36 and 0.28 (mathematics), 0.37 and 0.36 (science) and 0.42 and 0.41 (mother tongue). Table 6 gives the overlap of computer topics taught in the classrooms and the topics covered in teacher training courses. 
Table 6: Median Percent of Topics Coverd in Training, Given the Computer Topics Taught in the Existing Subjects

\begin{tabular}{lcc}
\hline & \multicolumn{2}{c}{ median \% } \\
Teachers & lower secondary education & upper secondary education \\
\hline overall & 69 & 75 \\
mathematics & 75 & 80 \\
science & 67 & 67 \\
mother tongue & 67 & 75 \\
\hline
\end{tabular}

These results show that a majority of computer topics which are covered in the lessons in the subject matter class, was also included in the training teachers received. A conclusion based on these findings is that content of training is an important reference for what is actually taught in the lessons. On the other hand, we must be careful to conclude that whatever is taught about in teacher training will also be covered in the instructional practice of the teacher in the class. It is actually found that of all topics included in the list, only $18 \%$ in lower secondary education and $25 \%$ in upper secondary education (across all subject matter areas) is also taught in the classrooms. The implication of these findings is that it seems important to carefully consider which topics to include in training for existing subject matter teachers and which not. This finding, together with the earlier raised interest to find out what topics were actually covered in teacher training, leads to the following section.

\section{Content of Training}

Pelgrum and Plomp (1991) mention that applications and problem analysis and programming are the most important topics dealt with during teacher training. Pedagogical/instructional aspects are the least mentioned topics of training, but computerusing teachers mention the inclusion of the topics in training more often than non-users. As indicated before, we hypothesize that those teachers who have had some training in the pedagogical/instructional aspects of computer use, tend to use the computer more for instructional purposes, compared to those who did not receive training in this area.

For this reason, a test on differences of means for all four subgroups of teachers was done on all 31 training topics. For lower secondary education, 27 training topics show a difference between the non-using group and the users. Of these topics, 20 show also a difference between the group of low integrators and high integrators. These topics are shown in Table 7. As can be seen from this table, only on one training topic a difference for all four subgroups of teachers is found ('evaluation of software'). In upper 
secondary education also 27 training topics show a difference between non-users and users. Of these topics 13 show a difference between the group of low integrators and high integrators.

Table 7: Training Topics Showing a Significant Difference Between Non-Using Teachers and Using Teachers as well as a Significant Difference Between Low and High Integrators

\begin{tabular}{|l|}
\hline Training topıcs in subscales \\
\hline Lower secondary education \\
Computers and society, \\
history/evolution \\
impact of computer applıcatıons (e g. socıal, economical) \\
ethical issues \\
Applicatıons: \\
spreadsheets \\
database management \\
models and simulations \\
telecommunications (e.g. electronic mal)/networks \\
educational games / recreational games \\
Problem analysis and programming: \\
general concepts \\
general procedures \\
structure of programs (e.g. input, output, storage of data flow \\
control) \\
programming languages \\
problem analysis (problem analysis and programming) \\
Principles of hard-and software structure. \\
basic concepts about computers and computer systems \\
hardware \\
software \\
Pedagogical/1nstructional aspects. \\
application of drill/practice/tutorial programs \\
locate overviews of existing software \\
evaluation of software* \\
integration of software in existıng lessons \\
organizatıon of computer use during lessons
\end{tabular}

* This item shows a significant difference for all pairs of subgroups of teachers 
(Table 7 continued)

Training topics in subscales
Upper secondary education
Computers and society:
history/evolution
impact of computer applications (e.g. social, economical)
Applications:
drawing/painting/illustrating
database management
models and simulations
educational games / recreational games
music generation
Problem analysis and programming:
structure of programs (e.g. 1nput, output, storage of data flow
control)
Principles of hard- and software structure.
basic concepts about computers and computer systems
software
Pedagogical/instructional aspects:
application of drill/practice/tutorial programs
evaluation of software
organization of computer use during lessons

In general, all topics in the categories 'problem analysis and programming', 'principles of hard- and software structure', and 'pedagogical/instructional aspects' distinguish low from high integrators in lower secondary education. However, when looking at both populations, pedagogical/instructional aspects (and particularly evaluation of software), seems to be the most distinguishing category of training topics. Thus, the hypothesis is confirmed that being trained in pedagogical/instructional aspects of computer use can be considered a contribution for the amount of integrated use. Because these topics were the least mentioned by teachers, an important conclusion from these findings is that pedagogical and instructional aspects need to be included much more in teacher training activities. Other activities which seem to be relevant for distinguishing different subgroups are some topics related to applications, problem analysis and programming and principals of hardware and software structures. Surprisingly, having had training in the use of educational and recreational games distinguishes low from high integrators.

Communication/Interaction

Staff development includes more than teacher training only (Orlich, 1989). Informal interaction, communication and team building are also important characteristics of staff development in the school (Fullan \& Stiegelbauer, 1991). 

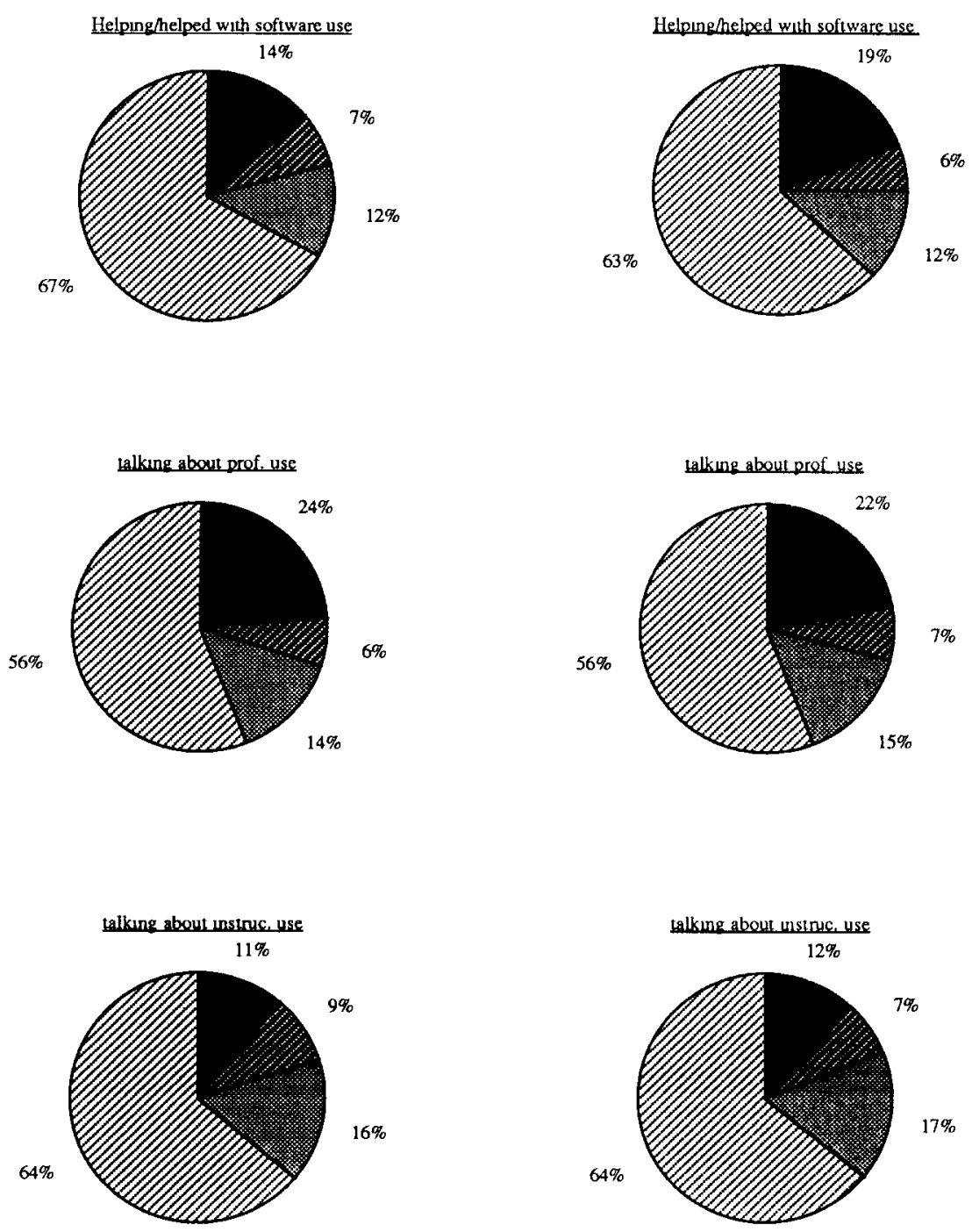

lower secondary education

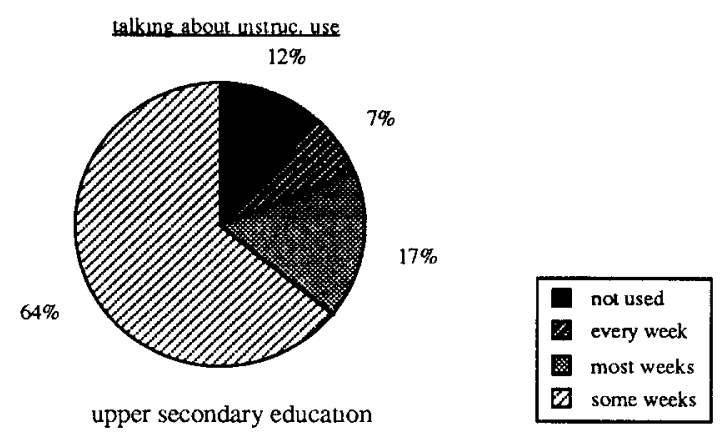

Figure 1: Frequency (in percent) of Each Type of Communication/Interaction for the Total Group of Computer-Using Existing Subject Teachers 
As Pelgrum and Plomp (1991) report, the Comped study provides some information about informal interaction and communication between computer-using teachers. They conclude that computer education teachers as well as computer-using teachers in existing subjects have many informal contacts with their colleagues within the school. The frequency of these interactions for all computer using existing subject teachers is indicated in Figure 1. The figure shows that most contacts take place during some weeks of the school year. Combining the categories of 'most weeks' and 'every week' communication, the most important activity among teachers is 'talking about instructional uses'. The three subgroups of using existing subject teachers do not differ significantly on these activities. It is not possible to distinguish which of the three activities is the most important for certain subgroups of integrators, because a majority $(>2 / 3)$ of all computer using existing subject teachers indicate that they are involved in all three types of activities.

These findings require at least two remarks. Firstly the frequency in which the interactions occur overall is so low that it is difficult to distinguish between the groups of users. Secondly the questions dealing with communication/interaction were stated quite globally in the instruments and therefore it might be possible that no effect is found of this variable on the degree of integration of computer in the class. However, Becker (1992) found that the existence of a social network of computer-using teachers at the same school distinguish exemplary teachers from other computer-using teachers, thus indicating that communication and team building seem to be important.

\section{Conclusions/Implications}

As indicated in this paper, staff development might not be the only contributor to the integration of the computer in the actual practice in existing subjects, but it is an important factor to look at. An analysis on the number of years teachers work with the computer for instructional purposes shows that more integration of the computer can be expected when a teacher works longer with the computer. Apparently, computer integration is such a complex innovation that it cannot be expected to be fully implemented within a short period of time.

Concerning teacher training, a series of results could be reported. The knowledge and skill base of teachers is related to training received and this relation is found to be significant.

Furthermore, the amount of training received and the type of topics covered in training are to some extent related to the amount of computer integration. Becker (1992), having developed a more complex measure for distinguishing exemplary computer using teachers from other computer users, also found organized support for computer using teachers in the form of staff development activities as one of the distinguishing factors for exemplary teachers. One of the most consistent findings on the environment of exemplary computerusing teachers is that they work at schools in districts that have invested heavily in staff development and on-site staff support for computer-using teachers. A conclusion from these findings is that a closer look at the types of teacher training is necessary in order to find out how many and which topics should be included. An indication of what topics should be included in teacher training is explored, leading to the conclusion that the inclusion of special pedagogical/instructional aspects in teacher training contribute to the integration of computers in the classroom. Besides, some topics in the category 
applications, program analysis and programming, and principles of hard and software structure seem to be relevant. Becker (1992) found that instruction in using computer application programs (such as word processors, spreadsheets and grade book managers) and formal training in using computers in teachers' specific subject matter are the two staff development activities which are especially important to distinguish exemplary teachers from the others. As our results show that particular pedagogical/instructional aspects only had a limited presence in the training activities up till 1989, an important implication from these results is that teacher training institutes should take these aspects into account.

Besides training, the influence of communication and interaction on computer integration was studied but no significant results on this relation were found. However, one may not conclude from these results that communication and interaction are not important in staff development. In the first stage of Comped, only a few variables concerning these aspects were included in the instruments and it might be that the operationalization of these aspects was not adequate. In stage two of Comped more detailed variables concerning this aspect are included in the instruments.

This paper presented data across countries. It is useful to study national situations concerning staff development as well, but in the scope of this paper, the country-specific information was excluded as argumented in the introduction. In this concluding section we can provide a first look at country-specific information. Within the group of using teachers, it is interesting to trace in which country the high integrators are located, and what per cent of all computer-using teachers are, according to our measure, high integrators. If they all would come from one country it would be logical to study for this specific country the way development activities are organized. If on the other hand, it would be found that high integrators are spread over all countries participating in the study, other conclusions need to be drawn.

A first exploratory analysis on the countries represented in the group of high integrators (as we defined it) reveals that the group of high integrators in lower secondary education mainly consists of teachers from France, USA and to some extent Austria. In upper secondary education the countries with the highest percentage of high integrators are India and USA. In most countries the group of high integrators as part of all using existing subject teachers does not exceed the $25 \%$ (except in upper secondary education in Austria, India and Israel). Although first analyses give some indications that in these countries more emphasis is laid upon pedagogical/instructional aspects in training activities, more thorough analysis is needed to draw firm conclusions.

\section{Summary}

Since the introduction of the computer in education, many authors claim that its beneficial aspects are related to the integration of computers in existing subjects. Research shows that staff development is one of the factors influencing the amount of computer integration. The data of the International Association for the Evaluation of Educational Achievement (IEA) international research project 'Computers in Education' (Comped) shed some light on the actual practice of staff development.

First of all, it is found that more integration of the computer is related to the number of years a teacher works with the computer. There is a significant relation between the knowledge and skills base of teachers and training received. To some extent, the amount 
of training received and the type of topics covered in training are related to computer integration. It is found that the inclusion of special pedagogical/instructional aspects of computer use in teacher training contributes to the integration of the computer in the curriculum. In the meantime, teachers indicate that in the training activities up till ' 89 these aspects are present only to a limited degree. As staff development includes more than just training, communication and interaction among teachers using computers was studied as well but no significant relation was found between the communication/interaction and computer integration.

\section{Note}

1. Drafts of this paper were presented at the convention of the Amencan Educational Research Association in San Francisco in Apri 1992, and the European Conference on Educational Research in Enschede (the Netherlands) in June 1992

\section{References}

Akker, van den, J.J.H. (1988). Ontwerp en implementatle van Natuuronderwiss (Design and implementation of science education). Amsterdam (the Netherlands): Swets \& Zeitlinger.

Becker, H.J. (1992). How our best computer using teachers differ from other teachers' Implications for realizing the potenttal of computers in schools. Paper presented at the AERA conference San Francisco, April 1992.

Brody, P.J. (1987). Computers in the classroom, infusing computers into the curriculum: Teacher preparation. Educational Technology, 28 (1), 34-35.

Codianni, A.V. \& Wilbur, G. (1983). More effective schooling from research to practice ERIC Clearinghouse on Urban Education. New York: Teachers College, Columbia University. ERIC/CUE Urban Diversity Series No.83 ERIC/EDRS 236299

Collıs, B. (1988). Computers, curriculum and whole-class instruction. Belmont (CA, USA): Wadsworth

Fullan, M.G. \& Stiegelbauer, S. (1991). The meaning of educational change. New York: Teachers College Press.

Hunter, B (1984). My students use computers. Reston (VA, USA): Reston Publıshing Company.

Moskowitz, J.H \& Birman, F (1985). Computers in the schools: 1mplications of change. Educational Technology, 25 (1), 7-14

Orlıch, D.C. (1989). Staff development enhancing human potential Boston: Washıngton State University.

Pelgrum, W.J. (1n preparation). Hardware and software provision in relation to the integration of computers. In: W.J. Pelgrum, \& Tj. Plomp (Eds.) Computers in education Implementation of an innovation in 20 countrles. 
Pelgrum, W J \& Plomp, TJ (1991) The use of computers in education worldwide Results from the IEA 'Computers in Education' survey in 19 Educatton Systems. Oxford: Pergamon.

Pelgrum, W J \& Schipper, A.T. (1992) Indicators of technology integration in education Enschede (the Netherlands): Department of Education, Unversity of Twente.

Stasz, C. \& Shavelson, R.J. (1985). Staff development for instructional uses of microcomputers AEDA Journal, 19 (1), 1-19.

Tobin, J (1988). Teacher training. In J Beishuizen, J Tobin \& P R. Weston (Eds), The use of the microcomputer in teaching and learning (pp. 223-233). Amsterdam (the Netherlands). Swets \& Zettlinger

Tuijnman, A.C., \& Brummelhu1s, ten, A C.A. (In preparation). Predıctıng computer use in six systems structural models of implementation indicators. In W.J Pelgrum, \& Tj. Plomp (Eds.), Computers in education Implementation of an innovation in 20 countries.

United States Congress (1988) Power on' New tools for teaching and learning. Washıngton: U.S Government Printing Office

Walker, DF (1986). Computers in the curriculum. In J A. Culbertson \& L L. Cunningham (Eds.), Microcomputers and education, Eighty-fifth yearbook of the National Soctety for the Study of Education (pp. 22-40) Chicago: University of Chicago Press

Zappone, F. (1991). Using technology in education Steps to the future Computers in the schools, 8 $(1 / 2 / 3), 83-87$.

\section{The Authors}

INGEBORG JANSSEN REINEN is researcher at the Center for Applied Educational Research (OCTO) of the Faculty of Educational Science and Technology, University of Twente in Enschede, the Netherlands. She is affiliated to the International Coordinating Center of the IEA study 'Computers in Education'.

TJEERD PLOMP is Professor of Education (educational technology, curriculum technology) in the Faculty of Educational Science and Technology, University of Twente in Enschede, the Netherlands. He is chaurman of IEA, the International Association for the Evaluation of Educational Achievement, and chatrman of the IEA study 'Computers in Education'. 